\title{
Engineering Geology Section at DGGS
}

Division of Geological \& Geophysical Surveys

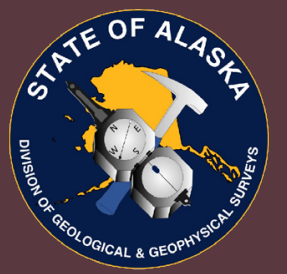

Engineering geologists identify where geologic processes are most likely to have an adverse impact on humans and the structures we build, and assure that the geological factors relevant to their location, design, construction, operation, and maintenance are recognized and accounted for.

DGGS' Engineering Geology section increases public safety and strengthens communities and infrastructure by providing geologic hazard, construction materials, and groundwater resources information and expertise across all 400 million acres of Alaska.

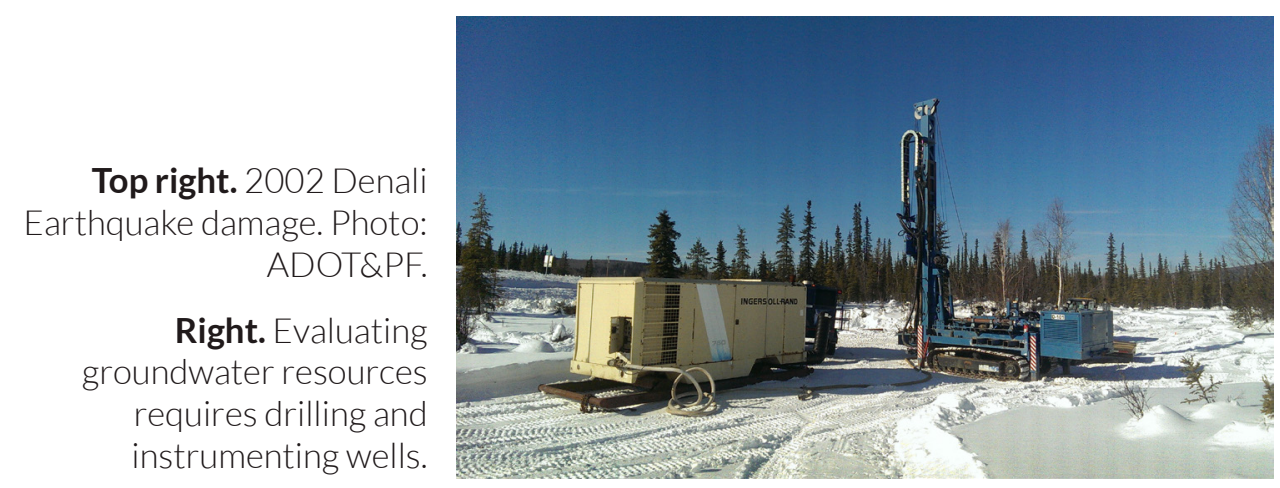

\section{Resource Development}

Aquifer modeling and mapping are essential to ensuring an adequate and safe supply of water for development and access for conventional and unconventional hydrocarbon resources on the North Slope and other areas of high potential. Surficial-geologic maps are used to locate valuable placermineral deposits and construction materials resources.

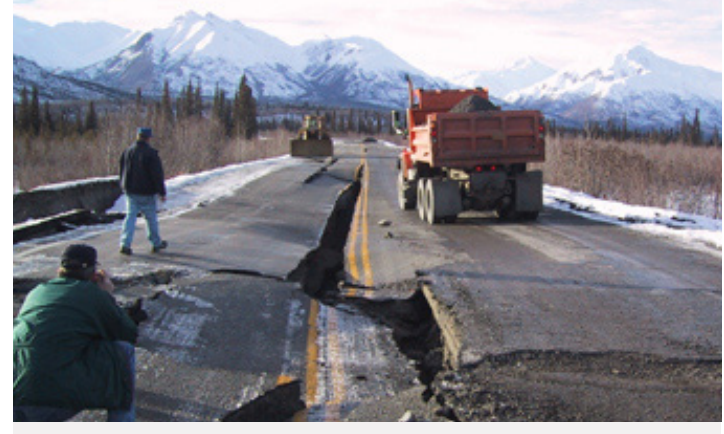

Incorporating engineeringgeologic analysis into decision making...

Supports informed land-use decisions by the government and private sectors.

Saves lives by identifying and mapping geohazards that pose a threat.

Protects infrastructure through understanding geologic conditions, processes, and hazards.

\section{Supports development}

by mapping the locations and quantities of available construction materials and water resources.

Saves the public and private sectors millions of dollars each year when projects are able to design for prevailing conditions. 


\section{Engineering Geology Section at DGGS}

Division of Geological \& Geophysical Surveys

\section{Infrastructure Maintenance \& Protection}

Engineering-geologic maps depicting construction materials resources are used to locate materials sources for highways, airports, and community and natural resource development. Creating and maintaining this infrastructure is necessary to support expanded development of natural resources and other economic activities in Alaska. Maps of permafrost conditions and slope stability characteristics help designers, planners, and repair crews plan and implement effective infrastructure development and maintenance.

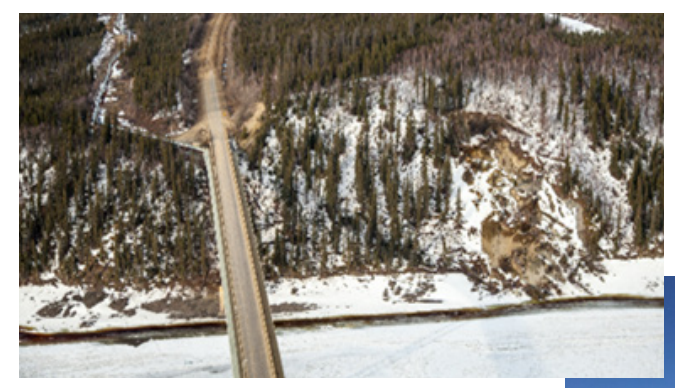

Left. Landslides such as this at the Yukon River bridge and Trans-Alaska Pipeline crossing threaten infrastructure and lives.

Below. DGGS snow surveys support avalanche forecasting and water resource management.

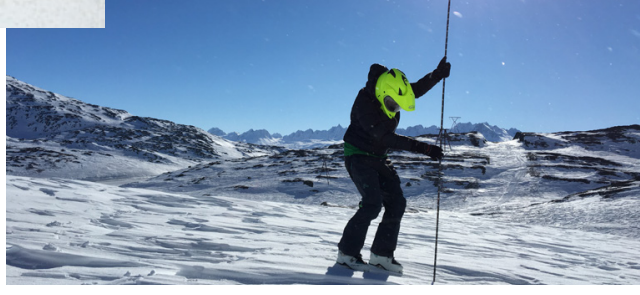

\section{Public Safety \& Community Resilience}

In many areas, Alaska lacks the fundamental geologic data needed to guide the proper development and implementation of building codes, land-use zoning, right-of-way siting, and contingency planning for natural hazards events. Maps produced by the Engineering Geology Section are the front-line source of information about where damage is likely to be greatest and where mitigation efforts should be concentrated. This lowers the costs of construction design and improves planning to mitigate consequences arising from hazardous geologic events and conditions.

Erosion, flooding, and thawing permafrost are a 3-punch threat to Alaska's communities and infrastructure. Photo: U.S. Geological Survey.

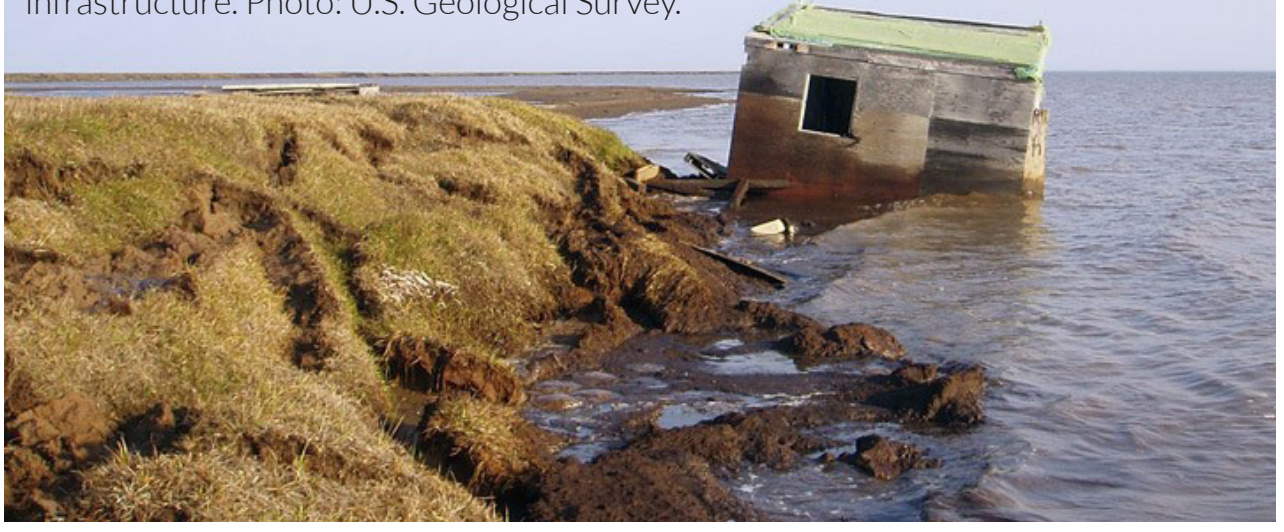

\section{Common Engineering Geology Terms}

Geologic hazard: Adverse geologic condition capable of causing damage or loss of property or life. Major geologic hazards impacting Alaska include flooding, erosion, avalanches, degrading permafrost, landslides, earthquakes, tsunamis, and volcanoes.

Construction materials: Naturally occurring rock and sediment deposits used by the construction industry. Common examples of construction materials include sand, gravel, and crushed stone (collectively known as aggregates); and riprap (large blocks and boulders of tough rock used to form a foundation or sustaining wall to prevent erosion).

Groundwater: Water that flows or seeps downward and saturates soil or rock, supplying springs and wells. Up to 18 barrels of fresh water-almost 570 gallons-are needed to produce one barrel of conventional crude oil. Permafrost and groundwater are strongly linked in Alaska.

Placer minerals: Natural accumulations of heavy minerals in stream or beach sand and river gravel. Gold is the most common economic placer mineral in Alaska. Most placer mining operations in Alaska are small, but combined they contribute over $\$ 100$ million a year to the state's economy.

Cryosphere: Those portions of Earth's surface and subsurface where water is in solid form, including sea ice, lake ice, river ice, snow cover, glaciers, ice caps, ice sheets, and frozen ground (permafrost).

Learn more online: dggs.alaska.gov

Or contact De Anne Stevens deanne.stevens@alaska.gov 907-451-5014

IC 76 | doi.org/10.14509/30122 